www.mjn.mosuljournals.com

\title{
Assessment of Quality of Life of Diabetic Patients Type-1- in Mosul City
}

Article information

Article history:

Received May 1, 2018

Accepted January 20, 2019

Available online July 3, 2018

DOI: 10.33899/mjn.2018.162872 @2020, College of Nursing, University of Mosul.

Creative Commons Attribution 4.0 International License

https://mjn.mosuljournals.com/article_162872.html

\section{Salwa Hazim Ghailan ${ }^{1}$}

Ma'an Ahmad Fadhil Al-Akaily ${ }^{2}$

\section{Abstract}

The aim of the study was to assess health problems related to Health Related of Quality of Life (HRQoL) of diabetic patients Type-1-, and to identify the relationship between some characteristics of diabetic patients Type-1- and health problems related to quality of life. This study uses the purposive approach. The study was conducted at Ibn-Sina hospital in Mosul city. The discruptive sample consists of (600) patients who visited Ibn-Sina hospital. In order to collect the study information, a questionnaire was constructed depending on previous studies and related literature review. It is composed of two parts: part one included (6) items which focus on the diabetic patients demographic characteristics such as (sex, age, marital status, occupation, educational level and residence). Part two was composed of (5) main items that covered independency, daily physical activities, psycho-social aspects, beliefs and environment. The total questions included (80) items, three scale options were used in the rating scale: (0) for never, (1) for sometimes and (2) for always. Content validity was determined by presenting the questionnaire to a panel of (12) experts. Internal consistency of the questionnaire was assessed by calculating Cronbach's Coefficient alpha. The data analysis shows that there is a significant statistical association between (HRQoL) items that are related to independency, daily physical activities, psycho-social aspects, beliefs and environment domains. The researcher concluded that (HRQoL) can be measured by instrument and that diabetic patients' independency, daily physical activities, psycho-social aspects, beliefs and environment were affected by their demographic characteristics (sex, age, marital status, occupation, educational level and residence). Depending on the findings and conclusions of the study, the researcher recommended further studies which could improve the instrument of this study from the view point of validity, reliability, and quality of questions.

\footnotetext{
${ }^{1}$ Lecture in Nursing College

${ }^{2}$ Directorate of Health, Mosul, Iraq
} 


\section{Mosul Journal of Nursing, Vol. 6, No. 2, 2018 ( 60-73 )}

\section{Introduction}

Diabetes mellitus is globally one of the most common non - communicable diseases at present. It is the fourth or fifth leading cause of death in most developed countries. Complications from diabetes such as coronary artery and peripheral vascular disease, stroke, nephropathy, neuropathy, amputations and blindness are resulting in increasing disability, reduced life expectancy health cost for most societies.

\section{Importance of the study:}

1-Diabetes mellitus is a chronic disease and nursing care is critical in its management, so optimal care with the best quality should be provided for long time need high costs due to bad economic for patient and his family (WHO, 2010).

2-There will be continuous increase in the number of individuals with diabetic disease and increase mortality rate in the next few years in our country due to consequent bad quality of life (Donnelly, 2011).

3-Quality of life is an important concept in the diabetic patients because the physical, psychological and social well-being of the patient are affected by the disease and related treatment (ADA, 2014).

4-Recently, studies have investigated the potential use of quality of life in Ibn-Sina hospital for diabetic treatment and research, but improving health and delivery of care for diabetic patient Type$1-$, how to respond to and screen physical, psychological and social problems must be known.

5-Quality of life is influenced by how well nurse is able to help diabetic patient Type1- and his family to respond to and be aware of disease risk and complications (WHO, 2010).

\section{Methodology:}

\section{Administrative Arrangements:}

An official permission was obtained from Ministry of Health, Department of Health in Ninavah to ensure its acceptance in order to conduct the study, and to arrange interviews with patients.

\section{Design of the study:}

Discruptive study of Health Related Quality of Life covering (600) diabetic patients Type-1- during the period of 15th January, 2018 to 15th April, 2018 was carried out at Ibn-Sina hospital in Mosul city.

\section{The sample of the study:}

Purposive sampling technique was used. This sampling technique is concerned with choosing participants based on their routine diabetes hospital visits and were able to communicate with the researcher. In this study, the patients aged between $(15$ - 35) years with Type-1-, who met the inclusion criteria and received care and follow-up for their diabetes at Ibn-Sina hospital in Mosul city. The study includes (600) patients with diabetes mellitus only.

\section{The study instrument:}

World Health Organization Qulaity of Life 100 and Brief, the Sickness Impact 


\section{Mosul Journal of Nursing, Vol. 6, No. 2, 2018 ( 60-73 )}

Profile, diabetes specific quality of life and attitude 39. In addition to other review literatures, pilot interviews and the results of focus groups discussions all guided the composition and content of constructed diabetic HRQoL.

The items that make up the Diabetes Health related Quality of Life questionnaire are (80) items that are derived from the following sources:

(1)Review of literatures on diabetes and its treatment, problems and impact on adolescents and young adults life which provide the possibility for a more comprehensive and integrated understanding of Diabetic QoL issues.

(2)Adolescents and young adults who have Type-1-.

(3)Focus groups analysis and results.

Diabetic HRQoL questionnaire is the instrument that investigation constructed consists of (5) domains and (17) subdomains. The domains and sub-domains are:

A-Independent (20) items domain which is composed of (5) categories each includes: sleep and rest, diet, medication, performance, leisure and recreation.

B-Daily physical activities (16) items domain which is composed of (2) categories each includes: movement and mobility, daily body care.

C-Psycho-social (28) items domain which is composed of (6) categories each includes: relation with family and friends, mood emotional behavior, concentration and perception, self actualization and symptoms of anxiety and fear.

D-Beliefs (12) items domain which is composed of (3) categories each includes: spiritual, hope and future.

E-Environmental and circumstances items domain. The questions were rated on (3) point-Likert response scale on which the patient rated contains behavior problems that are unique to their condition with Type-1-. The score ranges between (0-160).

\section{Data Collection:}

Data were collected through the use of the constructed questionnaire and the interview technique as a means of such collection through out the period from 15th January, 2018 to 15th April, 2018.

Limitations of the study:

1.The study is limited to diabetic patients Type-1- depending on insulin who visit Ibn-Sina hospital to take management only.

2.Patients who are involved in the study random visit to Ibn-Sina hospital during a week.

3.The duration of each interview was between (15 - 30 mins).

4.The period of the study was from 15 th of January 2018 to the 15th of April 2018.

Table (4:1) Demographic Characteristics of the Study subjects (N=600) 


\begin{tabular}{|c|c|c|}
\hline Variables & No. & $\%$ \\
\hline \multicolumn{3}{|l|}{ (a) Sex } \\
\hline Male & 272 & 45.34 \\
\hline Female & 328 & 54.66 \\
\hline Total & 600 & $100 \%$ \\
\hline \multicolumn{3}{|l|}{ (b) Age } \\
\hline $15-20 y$ & 159 & 26.50 \\
\hline $20-25 \mathrm{y}$ & 122 & 20.34 \\
\hline $25-30 y$ & 103 & 17.16 \\
\hline $30-35 y$ & 216 & 36.00 \\
\hline Total & 600 & $100 \%$ \\
\hline \multicolumn{3}{|l|}{ (c) Marital status } \\
\hline Single & 305 & 50.84 \\
\hline Married & 196 & 32.66 \\
\hline Widowed & 39 & 6.50 \\
\hline Divorced & 60 & 10.00 \\
\hline Total & 600 & $100 \%$ \\
\hline \multicolumn{3}{|l|}{ (d) Occupation } \\
\hline Pupil & 141 & 23.50 \\
\hline Worker & 201 & 33.60 \\
\hline Housewife & 187 & 31.10 \\
\hline Officer & 71 & 11.80 \\
\hline Total & 600 & $100 \%$ \\
\hline \multicolumn{3}{|l|}{ (e) Educational level } \\
\hline Illiteracy & 65 & 10.83 \\
\hline Primary school & 240 & 40.00 \\
\hline Secondary school & 77 & 12.84 \\
\hline Intermediate school & 87 & 14.50 \\
\hline Institutes & 99 & 16.50 \\
\hline University or above & 32 & 5.33 \\
\hline Total & 600 & $100 \%$ \\
\hline \multicolumn{3}{|l|}{ (f) Residence } \\
\hline Urban & 434 & 72.34 \\
\hline Rural & 166 & 27.66 \\
\hline Total & 600 & $100 \%$ \\
\hline
\end{tabular}

Table (4.1) demonstrates demographic characteristics of the study sample. The table shows that high percentage is female and consisted $(54.66 \%)$. The majority of diabetic patients Type-1- aged between (30-35) years, which represented $(36.00 \%)$. With regard to marital status, the table shows that $(50.84 \%)$ of them were single while $(6.50 \%)$ of them were widows. In the study of occupations of diabetic patients, the workers formed the highest percentage $(33.60 \%)$, while the lowest percentage of the officers was $(11.80 \%)$. The educational level of diabetic patients, the highest percentage was $(40.00 \%)$ who were graduated from primary schools, while only (5.33\%) of them were university graduates or above as the lowest percentage. With relation to their residence, the majority of the subjects $(72.34 \%)$ were living in urban areas but the rural areas were $(27.66 \%)$ only. The educational level of diabetic patients, the highest percentage was $(40.00 \%)$ who were graduated from primary schools, while only (5.33\%) of them were 


\section{Mosul Journal of Nursing, Vol. 6, No. 2, 2018 ( 60-73 )}

university graduates or above as the lowest living in urban areas but the rural areas were percentage. With relation to their residence, $(27.66 \%)$ only.

the majority of the subjects $(72.34 \%)$ were

Table (4:2) diabetic patient's responses on independency domains within 3-level scale by total frequencies, percentages and Chi-Square.

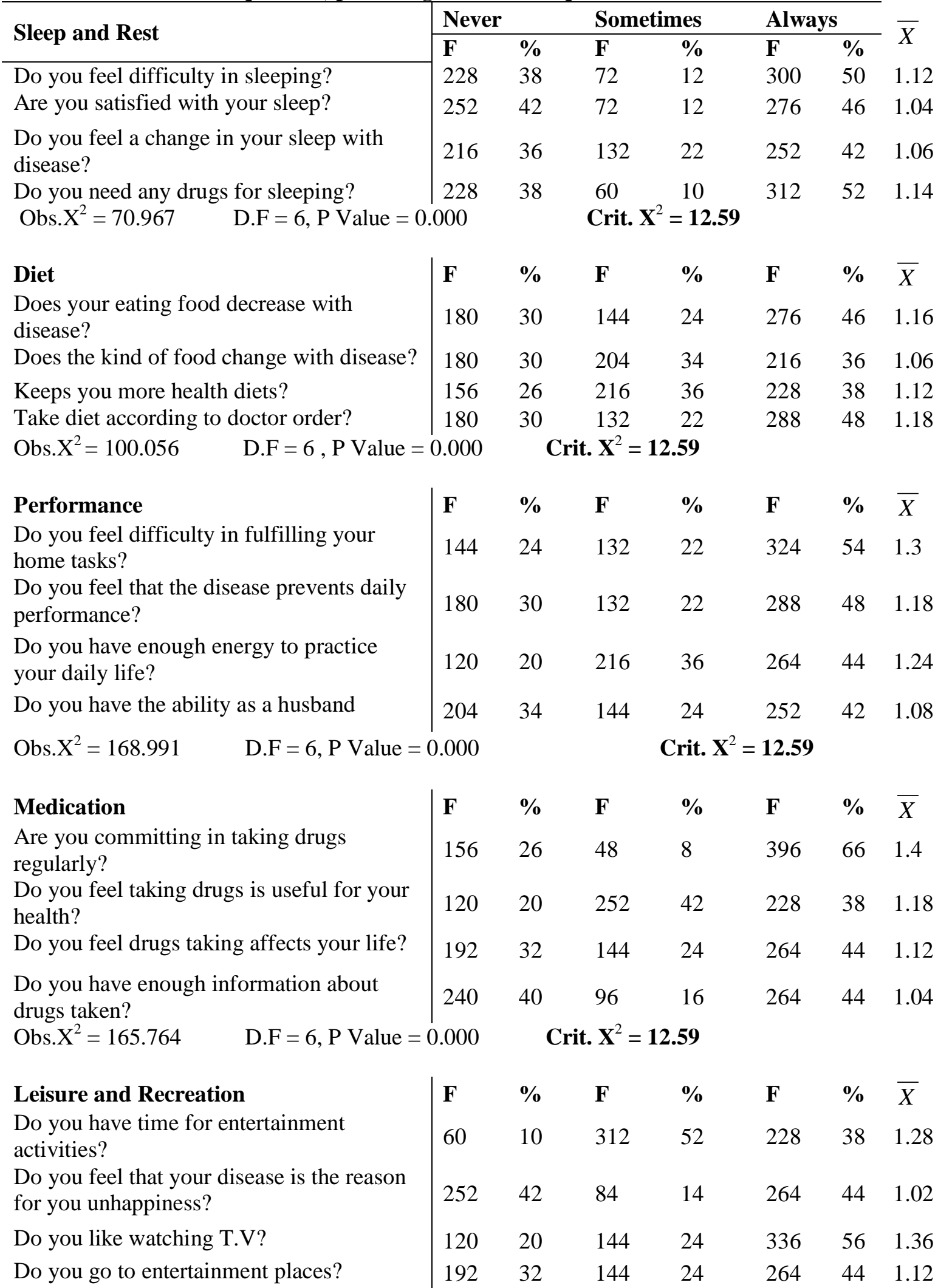


$\begin{array}{lll}\text { Obs. } X^{2}=165.764 & \text { D.F }=6, P \text { Value }=0.000 & \text { Crit } . X^{2}=\mathbf{1 2 . 5 9}\end{array}$

The table shows significant differences at $(\mathrm{P}$ Value $=0.05)$ of independency domains.

Table (4:3) diabetic patient's responses on daily physical activities domains with in 3- level scale by total frequencies, percentages and Chi-Square.

\begin{tabular}{|c|c|c|c|c|c|c|}
\hline \multirow{2}{*}{ Movement and Mobility } & \multicolumn{2}{|c|}{ Never } & \multicolumn{2}{|c|}{ Sometimes } & \multicolumn{2}{|c|}{ Always } \\
\hline & $\mathbf{F}$ & $\%$ & $\mathbf{F}$ & $\%$ & $\mathbf{F}$ & $\%$ \\
\hline $\begin{array}{l}\text { Is there difficulty as you put on your } \\
\text { clothes? }\end{array}$ & 36 & 6 & 324 & 54 & 240 & 40 \\
\hline $\begin{array}{l}\text { Is there difficulty as you walk and move in } \\
\text { long distances? }\end{array}$ & 108 & 18 & 252 & 42 & 240 & 40 \\
\hline $\begin{array}{l}\text { Do you have the ability to practice athletic } \\
\text { activities? }\end{array}$ & 204 & 34 & 192 & 32 & 204 & 34 \\
\hline Are you able to wander easily? & 240 & 40 & 96 & 16 & 264 & 44 \\
\hline $\begin{array}{l}\text { Do you have a difficulty when you have a } \\
\text { bath? }\end{array}$ & 156 & 26 & 156 & 26 & 288 & 48 \\
\hline Do you have slow motion? & 132 & 22 & 180 & 30 & 288 & 48 \\
\hline Going up do you need help during stairs? & 168 & 28 & 132 & 22 & 300 & 50 \\
\hline Is there difficulty as you move at home? & 72 & 12 & 276 & 46 & 252 & 42 \\
\hline
\end{tabular}

Obs. $\mathrm{X}^{2}=287.154 \quad$ D.F $=12, \mathrm{P}$ Value $=0.000$

Crit. $X^{2}=21.03$

Daily body care

Do you feel satisfied by health services

provided?

Are you satisfied about your health?

Do you always care well for your health?

Your family caring with your health.

Do you feel any advantage when you visit health centers?

Do you follow the health guidance?

Do you like bathing daily?

Do you help your family when visit

diabetic center?

Obs. $X^{2}=287.154 \quad$ D.F $=12, P$ Value $=0.000$

$\begin{array}{lllllll}\mathbf{F} & \boldsymbol{\%} & \mathbf{F} & \boldsymbol{\%} & \mathbf{F} & \boldsymbol{\%} & \bar{X} \\ 215 & 35.8 & 79 & 13.2 & 306 & 51 & 1.15 \\ 240 & 40 & 80 & 13.3 & 280 & 46 & 1.06 \\ 165 & 27.5 & 195 & 32.5 & 240 & 40 & 1.12 \\ 175 & 29.2 & 217 & 36.1 & 208 & 34 & 1.05 \\ 185 & 30.8 & 132 & 22 & 283 & .2 & 1.16 \\ 200 & 33.3 & 192 & 32 & 208 & 34 & 1.01 \\ 240 & 40 & 96 & 16 & 264 & 44 & 1.04 \\ 156 & 26 & 156 & 26 & 288 & 48 & 1.22\end{array}$

Crit. $X^{2}=21.03$

The table indicates significant differences at $(\mathrm{P}$ Value $=0.05)$ of daily physical activities domains.

Table (4:4) diabetic patient's responses on psycho-social aspects domains within 3-level scale by total frequencies, percentages and Chi-Square.

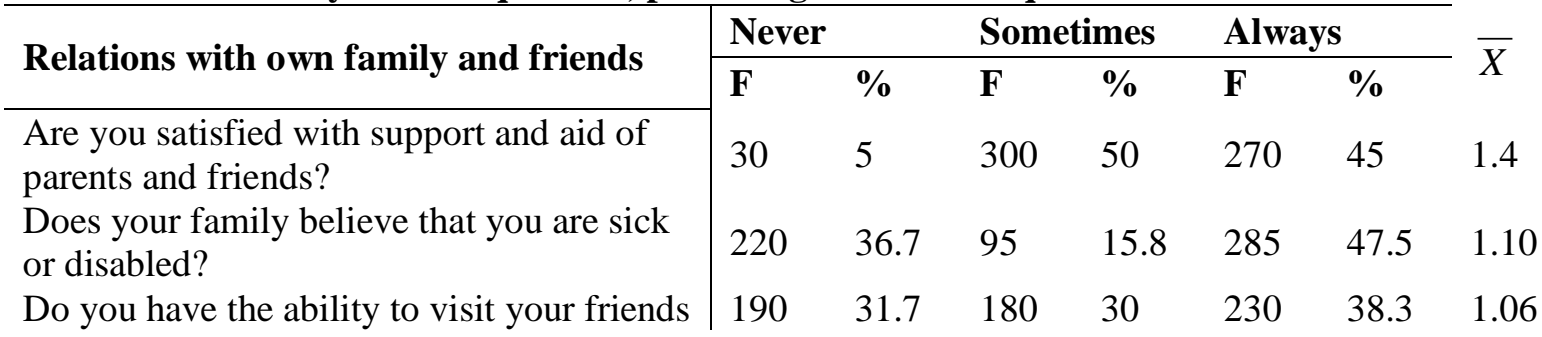


and relatives?

Do your friends understand your health condition?

$\begin{array}{lllllll}216 & 36 & 130 & 21.7 & 254 & 42.3 & 1.06\end{array}$

Do you effected disease about relation with your family?

Is your relation with your wife and family good?

Do you participate in making decisions inside home?

Obs. $X^{2}=274.273 \quad$ D.F $=12, P$ Value $=0.000$

$\begin{array}{lllllll}165 & 27.5 & 232 & 38.7 & 203 & 33.8 & 1.06\end{array}$

$\begin{array}{lllllll}201 & 33.5 & 173 & 28.8 & 226 & 37.7 & 1.04\end{array}$

$\begin{array}{lllllll}79 & 13.2 & 263 & 43.8 & 258 & 43 & 1.29\end{array}$

$\begin{array}{lllllll}243 & 40.5 & 76 & 12.7 & 281 & 46.8 & 1.06\end{array}$

Crit. $X^{2}=21.03$

Mood

Do you feel annoyed when you visit health centers?

Do you feel happy in your life?

Do you feel annoyed of noise?

Do you prefer not to mix with others?

\begin{tabular}{|lll}
$\mathbf{F}$ & $\mathbf{\%}$ & $\mathbf{F}$ \\
208 & 34.7 & 70 \\
252 & 42 & 72 \\
242 & 40.3 & 82 \\
228 & 38 & 60
\end{tabular}

Obs. $X^{2}=239.998$

D.F $=12, P$ Value $=0.000$

Emotional behavior
Do you feel that affected disease is behind
the kindness of others?
Does your passion increase with your
affected disease?
Do you feel loosing passion as affected
disease?

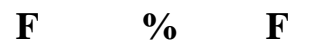

$216 \quad 36 \quad 148$

$180 \quad 30 \quad 200$

$156-26=-216$

$\begin{array}{lll}156 & 26 & 216\end{array}$

Increase your family kindness after disease. 180

Obs. $X^{2}=3.999$

D.F $=6, P$ Value $=0.000$

\section{Concentration and perception}

Do you have the ability to concentrate?

Do you feel that your memory is affected at now?

Do you feel that you can remember things

happened in the past?

Do you feel that level of education

decrease because of disease?

30

132

$\% \quad$ F

$11.7 \quad 322$

$\% \quad \bar{X}$

$12 \quad 276$

$13.7 \quad 276$

$10 \quad 312$

Crit. $X^{2}=21.03$

53

1.19

$\begin{array}{ll}46 & 1.04\end{array}$

$\begin{array}{ll}46 & 1.05\end{array}$

$52 \quad 1.14$

\footnotetext{
Crit. $X^{2}=21.03$
}

$\%$

F

$\% \quad \bar{X}$

Obs.X2 $=49.717$

D.F $=6, P$ Value $=0.000$

\begin{tabular}{|lll}
$\mathbf{F}$ & $\boldsymbol{\%}$ & $\mathbf{F}$ \\
230 & 38.3 & 55 \\
220 & 36.7 & 95 \\
190 & 31.7 & 170 \\
206 & 34.3 & 130
\end{tabular}

$\%$

$9.2 \quad 315$

\% $\bar{X}$

$\begin{array}{llll}15.8 & 285 & 47 & 1.10\end{array}$

$\begin{array}{llll}28.3 & 240 & 40 & 1.08\end{array}$

$\begin{array}{llll}21.7 & 264 & 44 & 1.09\end{array}$

Crit. X2 = 12.59

\section{Self actualization}

Are you satisfied with yourself?

Are you satisfied with your role in life?

\begin{tabular}{|lll}
$\mathbf{F}$ & $\mathbf{\%}$ & $\mathbf{F}$ \\
222 & 37 & 155 \\
200 & 33.3 & 170 \\
79 & 13.2 & 263 \\
243 & 40.5 & 72
\end{tabular}

achieved in your life?

Achieved yourself?

243

Obs. $X^{2}=79.532$

D.F $=6, P$ Value $=0.000$

\section{Symptoms of anxiety and fear}

Do you anxiety and fearful?

Do you have a feeling of sadness and

depression?

Do you feel frightened?

Do fear and anxiety domiant your life?

\begin{tabular}{|lll}
$\mathbf{F}$ & $\mathbf{\%}$ & $\mathbf{F}$ \\
228 & 38 & 72 \\
195 & 32.5 & 165 \\
190 & 31.7 & 180 \\
200 & 33.3 & 192
\end{tabular}

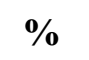

\section{F}

25.8

28.3

223

230

$43.8 \quad 258$

12

Crit. $X^{2}=12.59$

$\begin{array}{llll}\% & \text { F } & \% & \bar{X}\end{array}$

$\begin{array}{llll}12 & 300 & 50 & 1.12\end{array}$

$\begin{array}{llll}27.5 & 240 & 40 & 1.6\end{array}$

$\begin{array}{llll}30 & 230 & 38 & 1.06\end{array}$

$\begin{array}{llll}32 & 208 & 34 & 1.01\end{array}$ 

Obs. $X^{2}=83.960$
D.F $=6, \mathrm{P}$ Value $=0.000$
Crit. $X^{2}=12.59$

The table shows significant differences at $(\mathrm{P}$ Value $=0.05)$ of psycho-social aspects domains.

Table (4:5) diabetic patient's responses on beliefs domains within 3-level scale by total frequencies, percentages and Chi-Square.

\begin{tabular}{|c|c|c|c|c|c|c|c|}
\hline \multirow{2}{*}{ Spiritual } & \multicolumn{2}{|c|}{ Never } & \multicolumn{2}{|c|}{ Sometimes } & \multicolumn{2}{|c|}{ Always } & \multirow{2}{*}{$\bar{X}$} \\
\hline & $\mathbf{F}$ & $\%$ & $\mathbf{F}$ & $\%$ & $\mathbf{F}$ & $\%$ & \\
\hline Are you able to go to worship position? & & 36.7 & 95 & 15.8 & 285 & 47.5 & 1.10 \\
\hline Does your disease made you prayer? & 90 & 31.7 & 170 & 28.3 & 240 & 40 & 1.08 \\
\hline Do religious beliefs affect your health? & 30 & 5 & 300 & 50 & 270 & 45 & 1.4 \\
\hline $\begin{array}{l}\text { Do you try to employ spiritual beliefs for } \\
\text { therapy? }\end{array}$ & 216 & 36 & 148 & 24.7 & 236 & 39.3 & 1.03 \\
\hline Obs. $X^{2}=82.057 \quad$ D.F $=6, P$ Value & \multicolumn{2}{|c|}{$\mathrm{D} . \mathrm{F}=6, \mathrm{P}$ Value $=0.000$} & \multicolumn{4}{|c|}{ Crit. $X^{2}=12.59$} & \\
\hline Hope & $\mathbf{F}$ & $\%$ & $\mathbf{F}$ & $\%$ & $\mathbf{F}$ & $\%$ & $\bar{X}$ \\
\hline Do you like life in this time? & 235 & 39.2 & 95 & 15.8 & 270 & 45 & 1.05 \\
\hline Do you feel hope in your life? & 132 & 22 & 252 & 42 & 216 & 36 & 1.14 \\
\hline Do you think of death? & 60 & 10 & 312 & 52 & 228 & 38 & 1.28 \\
\hline Do you have a hope of recovery? & 243 & 40.5 & 72 & 12 & 285 & 47.5 & 1.07 \\
\hline \multicolumn{2}{|l|}{ Obs. $X^{2}=141.181 \quad$ D.F $=6$, } & \multicolumn{6}{|c|}{ Crit. $X^{2}=12.59$} \\
\hline Future & $\mathbf{F}$ & $\%$ & $\mathbf{F}$ & $\%$ & $\mathbf{F}$ & $\%$ & $\bar{X}$ \\
\hline $\begin{array}{l}\text { Do your feel that you lost your role in the } \\
\text { future? }\end{array}$ & 165 & 27.5 & 195 & 32.5 & 240 & 40 & 1.12 \\
\hline $\begin{array}{l}\text { Do your feel your health will improve } \\
\text { later? }\end{array}$ & 210 & 35 & 95 & 15.8 & 295 & 49.2 & 1.14 \\
\hline \multirow{2}{*}{$\begin{array}{l}\text { Are your afraid of the future? } \\
\text { Do you feel that your future will be better } \\
\text { than the past? }\end{array}$} & 216 & 36 & 130 & 21.7 & 254 & 42.3 & 1.06 \\
\hline & 228 & 38 & 72 & 12 & 300 & 50 & 1.12 \\
\hline
\end{tabular}

Obs. $X^{2}=60.771 \quad$ D.F $=6, P$ Value $=0.000$

Crit. $X^{2}=12.59$

The table shows significant differences at $(\mathrm{P}$ Value $=0.05)$ of beliefs domains.

Table (4:6) diabetic patient's responses on environment domains within 3-level scale by total frequencies, percentages and Chi-Square.

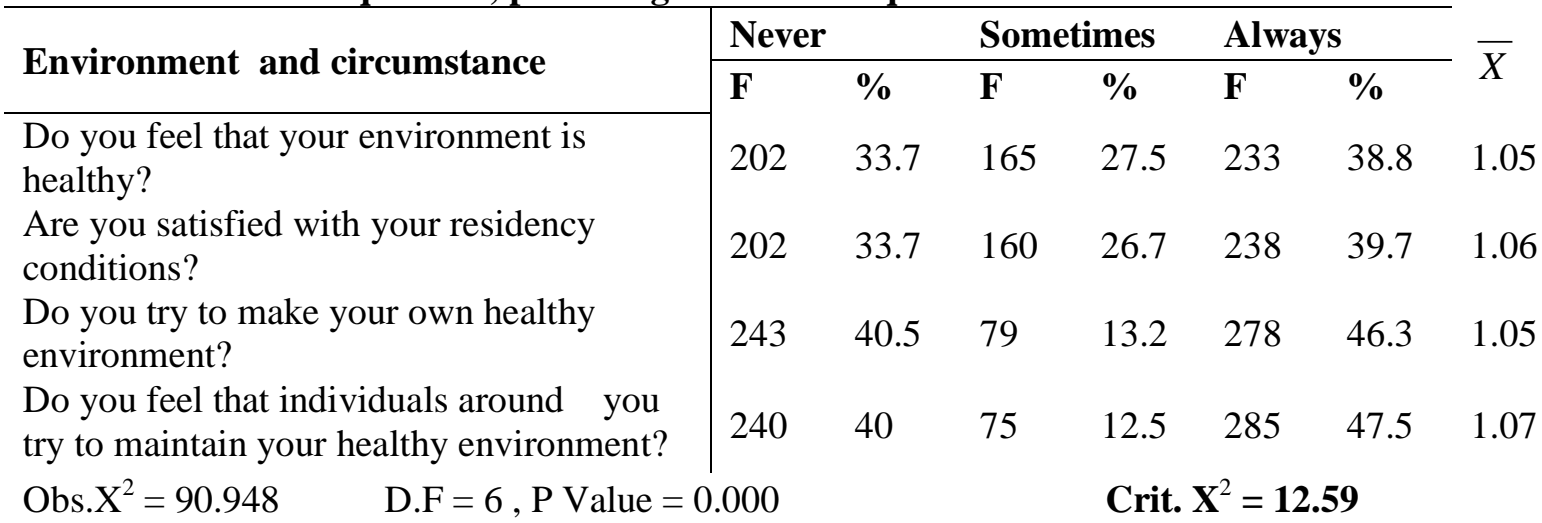

The table shows significant differences at $(\mathrm{P}$ Value $=0.05)$ of environment domains.

Part I: Discussion of HRQoL of diabetic patients Type-1-:

\section{Independency domains:}

The data analysis shows that there is a significant statistical association of health related quality of life items that are related to independency domains. The finding may be explained by the fact that health 


\section{Mosul Journal of Nursing, Vol. 6, No. 2, 2018 ( 60-73 )}

care services provided by the health care system are not efficient and do not take in to consideration the needs of these aggregates, which are reflected in the health problem that occurred to them. With relation to the independency domains, the diabetic patients suffered from sleep disorder, diet imbalance, difficulty in performance of their duties, medication compliance as well as recreation. Also, it was noticeable that the diabetic patients didn't gain the appropriate care that leads to the improvement of their quality of life.

Letassy (2013) mentioned that sleep disorder is a problem with some patients which reflects the underlying reaction to their physical problem in the form of anxiety and depressive illness. Letassy stated that some people who have had diabetic patients have difficulty in sleeping when they return home from center. This is due to change in environment from center and may be part of getting used to their night time routine and bed again. It may also be due to worry that diabetes mellitus will increase during the night.

Institute of Medicine Food and Nutrition Board (2010), mentioned that diet and exercises are considered important components of the treatment strategy for adults with diabetes. Appropriate use of diet and exercise can improve insulin sensitivity and glycemic control and decrease the need for oral medications or insulin. Although there is some controversy over the optimal diet for adults with diabetes (high fiber, glycemic index approaches, low versus moderate fat), there is a consensus to increase consumption of fruits and vegetables and decrease daily consumption of saturated fats.

Hawthorne and Tomlinson (2012) mentioned that the diabetic on diet usually needs to take no special precautions but the diabetic on insulin may need to take extra carbohydrate before or during exercise. The amount varies greatly and each diabetic should learn for himself what effect, if any, extra exertion has on his carbohydrate needs. They may be increased by $50 \mathrm{gs}$ or even more. It is generally better to raise carbohydrate intake than lower insulin dosage. There are some special considerations. Mountaineering and skiing may be dangerous. No diabetic on insulin should ever swim alone. In any case of doubt it is best to take extra carbohydrate before the exertion. It can give useful advice on personal, social, professional and other problems and diabetics are strongly recommended to belong. It runs holiday camps and cruises for children, publishes a handbook, guides to the carbohydrate values of foods and a journal.

\section{Daily physical activities domains:}

The study finding revealed that there is a significant statistical association of health related quality of life items which concerned with daily physical activities assessment. The main event that is noticed in the physical daily activities is that the 


\section{Mosul Journal of Nursing, Vol. 6, No. 2, 2018 ( 60-73 )}

maturity of the diabetic patients Type-1had difficulty in working.

Raile and others' studies have investigated the role of exercise on leptin. They observed a significant decrease in leptin among men after a 20 week endurance training program; however, the result was only marginally significant after adjustment for the reduction in fat mass. A week aerobic training program without changes in fat mass did not result in a change in leptin level in men, but the number of subjects was small. Conversely, others have found that lower leptin levels associated with activity, independent of changes in fat mass. He observed a lower level of leptin among rugby players when compared with sedentary individuals with similar body fat content and observed a decrease in leptin among obese subjects with increasing hours of exercise independent of percent age of body fat. In our analysis, the association of physical activity with leptin was only somewhat attenuated after adjustment to BMI. For decades, exercise has been considered a cornerstone of diabetes management, along with diet and medication. However, high-quality evidence on the importance of exercise and fitness in diabetes was lacking until recent years. The last American Diabetes Association (ADA) technical review of exercise and diabetes (formerly known as non-insulin dependent diabetes) was published in 2010 (Raile et. al., 2010).

Schneider and Guleria (2010) mentioned that physical activity plays an important role in the treatment protocol for DM. Among patients with T1DM, exercise has been found to improve metabolic control and to reduce exogenous insulin requirements. It may also prevent or delay late DM-related complications and improve longevity. Several factors influence the metabolic and hormonal responses to exercise among diabetic patients, such as the duration and intensity of exercise, the level of metabolic control, the type and dose of insulin delivered before exercise, the site of injection, and the timing of the previous insulin injection and food intake relative to the exercise. Accordingly, blood glucose levels can decline (the most common response), increase, or remain unchanged.

\section{Psycho-social aspects domains:}

The study finding revealed that there is a significant statistical association of health related quality of life items which measure with psycho-social aspects assessment.

Grey and others (2012) explained a number of studies, including metaanalyses, have shown the association between diabetes and depression. This is an important public health issue because depressive disorders generally have been associated with the outcomes of chronic diseases like diabetes and have contributed to the high economic burden of health care costs. Many of the studies have relied on clinical or other convenience samples in describing depression and diabetes as comorbid conditions or in exploring the 


\section{Mosul Journal of Nursing, Vol. 6, No. 2, 2018 ( 60-73 )}

association of depression with clinical markers such as glycemic control, blood pressure, cholesterol and triglyceride levels. Indeed, in a meta-analysis, it is reported that depression was more prevalent in clinical samples than in the community. However, there have been recent large population-based studies that have confirmed this association, concluded that the effects of depression in diabetes were not trivial. Several studies have assessed the impact of depression in diabetes in terms of the individual's functional ability or quality of life. $\mathrm{He}$ examined preference-based time tradeoff utility values associated with diabetes and showed that those with diabetes were willing to trade a significant proportion of their remaining life in return for a diabetes-free health state. One of the factors affecting quality of life in the diabetic group included depression. Understanding which dimensions of quality of life are associated with the comorbidities of depression and diabetes is important for day-to-day clinical management and also for public health policy initiatives aimed at improved health outcomes for the diabetic population. This is even more important given that diabetes is increasing in Australia and in many other industrialized countries.

\section{Beliefs domains:}

The study finding revealed that there is a significant statistical association of health related quality of life item which concern with beliefs assessment.
Kluckhohn and Strodtbeck (2011) explained an important area for consideration in planning nursing assessments and interventions, the function of religious and magical beliefs in human attempts to cope with the adversities of illness. Of particular interest would be the degree of fatalism expressed by cultural value orientations about humanity's ability to control diabetes.

Taylor and others (2015) explained numerous interventions promote spiritual well-being, including referral to a chaplain or clergy member; facilitating religious rituals, prayer, meditation and relaxation; providing spiritual music or art work; active listening; dialogue about spiritual matters; recommending spiritual reading material; and being therapeutically present that is, trusting, loving, vulnerable, empathic and humble. Because of the significant impact of meaning on quality of life, our discussion of spiritual care interventions will be limited to those related to the promotion of meaning and purpose.

\section{Environment domains:}

The study finding revealed that there is a significant statistical association of health related quality of life items which are concerned with environment assessment.

Glasgow and others (2017) mentioned that the mental state and environment status of the patient will affect the management of diabetes. Poor control may be due to a variety of factors: a basic failure; a financial struggle to meet the high prices 


\section{Mosul Journal of Nursing, Vol. 6, No. 2, 2018 ( 60-73 )}

of a protein-orientated diet, disharmony home or, in some countries, an inability to pay for essential drugs. Underprivileged families in the lower socio-economic strata are often less able to cope with the stress of life and it might be expected that they would have greater difficulty in controlling diabetes.

Explained that stress is invariably associated with modernized life style. Tremendously increased traffic in large cities, still increasing speed, exaggerated hastiness, frequent professional and family conflicts, injuries and the high frequency of vascular and other diseases states represent various types of stress. Stress of any kind means a load to which the human body reacts either by physiological or sometimes pathological responses.

\section{Conclusions:}

The findings are based on the results of data analysis. According to the objectives of this study, the conclusions are:

(1)The results of this study are interesting because that health problems related to quality of life of diabetic patients Type-1-, they are according to: (independency, daily physical activities, psycho-social aspects, beliefs and environment) domains. (2)Health related quality of life of diabetic patients Type-1- can be measured by instruments.

(3)The demographic characteristic of diabetic patients Type-1-: sex, age, marital status, occupation, educational level and residence directly affect: independency, daily physical activities, psycho-social aspects, beliefs and environment.

(4)This study is important because of need special staff of nursing that deal with diabetic patients bio-psychosocial wellbeing.

\section{Recommendations:}

Depending on the findings and conclusions of the study, the researcher recommended the following:

(1)Increase the number of centers of diabetic patients especially to improve quality of life in Mosul city with medical specialization and nursing teams to deal with physical, psychological and social problems of diabetic patients Type-1-.

(2)Affirmation to continue the same researches and studies related to quality of life in diabetic patients Type-1-, and avoidance of restriction of care about the physical problems only.

(3)Follow up diabetic patients Type-1Ibn-Sina hospital by calling and visiting them in their houses for psychological support and to prevent physical problems.

\section{References:}

ADA, Physical activity/ exercise and Type-1diabetes. Diabetes Care 2014; 27 (Suppl. 1): S58-S62.

Donnelly, R.; and Davis, K.R. (2011). Type 2 diabetes and atherosclerosis. Diabetes, obesity and metabolism 2 (suppl.): 521-530.

Glasgow, R.E.; Hampson, S.E.; Strycker, L.A.; and Ruggiero, L. Personal model beliefs and social-environmental barriers related to diabetes self-management. Diabetes Care 2017; 20(4): 556-561. 


\section{Mosul Journal of Nursing, Vol. 6, No. 2, 2018 ( 60-73 )}

Grey, M.; Whittemore, R.; and Tamborlane, W. Depression in Type-1- diabetes in children: natural history and correlates. J Psychosomat Res. 2012; 53: 907-911.

Hawthorne, K.; and Tomlinson, S. One-to-one teaching with pictures: flashcard health education for British Asians with diabetes. Br J Gen Pract 2012; 47: 301-304.

Hinds, T. and Health, B. Quality of life medical perceptions in long term therapy, $1^{\text {st }}$ edition, London, Jonsaid Bartlett Publisher, 2010, pp.145-147.

Kluckhohn, F.; and Strodtbeck, F. Variations in Value Orientations (Evanston, III.: Row, Peterson, 2011).

Letassy, (2013). Prevention and treatment of chronic diabetes complication. Diabetes Complications: 1-6.

Raile, K.; Kapellen, T.; Schweiger, A.; Hunkert, F.; Nietzschmann, U.; Dost, A.; and
Kiess, W. Physical activity and competitive sports in children and adolescents with type 1 diabetes. Diabetes Care 2010; 22: 1904-1905. Schneider, S.H.; and Guleria, P.S. Exercise and diabetes. In: Warren, M.P.; and Constantini, N.W. eds. Sports Endocrinology. Totowa, NJ: Humana Press; 2010: 227-238.

Taylor, E.J.; Amenta, M.O.; and Highfield, M.F. (January 2015). Spiritual care practices of oncology nursing. Oncology Nursing Forum.

WHO, Department of Non-communicable Disease Surveillance. Definition, diagnosis, and classification of diabetes mellitus and its complication. Report of a WHO consultation. Part 1: Diagnosis and classification of diabetes mellitus. Geneva: WHO 2010. 